\title{
NO INTERIOR DO CORPO POLÍTICO, OS SENTIDOS DA RESISTÊNCIA: A TESSITURA DE MAQUIAVEL
}

\author{
Fran de Oliveira Alavina ${ }^{1}$
}

\begin{abstract}
É um fato que a obra só existe se a acolhemos, se nos descobrimos investidos por ela, no momento em que a interrogamos; se perguntamos o que ela é sabendo que esta questão é ainda ela que faz nascer em seu leitor e que este deve se encarregar dela ou fazer dela a sua questão. (Claude Lefort, $A$ obra de pensamento e a história).
\end{abstract}

\begin{abstract}
Resumo: Ainda que Maquiavel não esteja no âmbito da tradição política dos pensadores que teorizaram sobre o direito de resistência, é possível se reportar à questão da resistência como elemento constituinte da vida política no pensamento do autor florentino. Tal pode ser realizado com base nos dois momentos em que o termo resistência, nas suas formas verbal e substantiva, ocorre no âmbito da argumentação do Príncipe. Aqui não se propõe um simples exercício de léxico político, satisfazendo-se com o reconhecimento e a localização do termo. É a própria concepção da escrita política em Maquiavel que possibilita pensar a pertinência do termo na reflexão política: questão justificada na primeira parte deste trabalho. Daí, fundamentando-se na natureza da escrita política, discorre-se sobre os dois momentos em que Maquiavel utiliza-se do termo resistência como meio de expressão e compreensão da relação entre virtù e fortuna, bem como da oposição entre os grandes e o povo.
\end{abstract}

Palavras-Chave: Língua - política - resistência.

\section{I - Excurso inicial: sobre a língua em que se inscreve a política}

Poderíamos, com efeito, no âmbito da obra O Príncipe, abordar um dos temas de nosso evento (II Jornada de Ética e Filosofia Política do Departamento de Filosofia da USP), a saber, Intervenção. É inconteste, quer pelo conteúdo da obra, quer pelo seu destinatário, que ela expressa uma daquelas características mais particulares da escrita política: de enquanto escrita ser também uma forma de intervenção. Nos termos de Lefort, uma escrita que é "fala singular, voltada para a exigência de desmanchar as armadilhas da crença ou de se subtrair à captura da ideologia, que se deixa levar sempre para além do lugar em que se espera (...)"2. Todavia, resguardada esta particularidade da escrita política, não iremos abordar a questão da intervenção. Trataremos, pois, da Resistência.

Talvez se possa objetar, já de início, que não há ao longo da argumentação do Príncipe, de fato, uma teoria sobre a resistência. É verdade, não encontraremos nesta obra

\footnotetext{
${ }^{1}$ Doutorando do Programa de Pós-Graduação em Filosofia da USP, sob a orientação do Prof. Luís César Oliva. Bolsista FAPESP, com o projeto, "Espinosa, leitor de Leão Hebreu: um estudo sobre o Breve Tratado".

2 LEFORT, Desafios da Escrita Política, p. 11.
} 
do agudíssimo florentino, para usarmos o epíteto espinosano, algo próximo daquilo que a Modernidade não apenas justificou filosoficamente, mas fundamentou como um direito: o direito de resistência. Contudo, uma leitura atenta e pertinaz do Príncipe faz ver ao leitor que Maquiavel utiliza o termo resistência: quer na sua forma verbal resistere, quer na sua forma substantiva resisten₹a. Utilização que ocorre em apenas dois momentos de sua argumentação no Príncipe.

Talvez ainda, os leitores mais desconfiados, por este nosso primeiro modo de abordarmos a questão, também objetem que se trataria aqui de uma simples operação de topologia textual. Em outras palavras, de apenas apontar os lugares do texto nos quais o termo é usado. Servindo, por isso, mais à curiosidade vocabular do que propriamente à reflexão filosófica. Ademais, ainda mantido no círculo das antecipações desconfiadas, talvez nosso leitor objete, por fim, que o simples uso do termo não poderá nos dar muito o que dizer. Todavia, reparem nossos leitores que no meio das argumentações dadas na obra, em que Maquiavel aponta inúmeros exemplos de artimanhas bélicas, testemunho de povos rebelados, conflitos civis, tiranias, usurpações de poder e tumultos fratricidas, o termo resistência e sua forma verbal resistir não fazem parte do cerne vocabular de tais exemplificações, conforme seria de se esperar, uma vez que o termo resistência é próprio do campo semântico das narrativas de guerras e das fissuras no tecido social.

Em geral, é no meio das crises e dos perigos que ameaçam a liberdade civil que o termo resistência ganha centralidade no vocabulário do discurso político, e seu sentido é dilatado no campo semântico dos ditos e escritos. Ora, como veremos, segundo nos apontam as razões maquiavelianas, a resistência não é a virtude nem o direito reclamados em momentos extraordinários da vida política. Isto é, a resistência não é simplesmente a reação justa dos que sofrem a injustiça, nem está presa à materialidade e à letra de uma lei que a garante. Ao contrário, a resistência está no interior e no curso ordinário do corpo político: difusa como relação dinâmica.

Isto já aponta para um tratamento particular com o termo, que não é usado nos lugares em que, por antecipação, nós, leitores modernos, esperamos encontrá-lo. Além do que, Maquiavel adverte no prefácio do Príncipe que: "Não ornei nem sobrecarreguei esta obra de longos periodos, nem de palavras pomposas e magnificas, nem de nenbum outro atrativo ou ornamento exterior com que muitos costumam descrever e ornar suas coisas, porque pretendi que coisa alguma a honrasse e que somente a variedade da matéria e a gravidade do assunto a fizessem agradável’’.

Com base nesta orientação, podemos corroborar a importância das duas vezes que Maquiavel utiliza o termo resistência, pois os usos dos termos não ocorrem por meras questões estilísticas. Não se trata de exterioridades, ou, nos termos do próprio autor, de

\footnotetext{
3 MAQUIAVEL, O Príncipe, p. 4. As citações do Príncipe são da tradução da editora Martins Fontes, porém sempre cotejadas com o original da edição feita em conjunto pelas editoras Einaudi-Gallimard, por isso nossa tradução diverge em alguns poucos momentos da tradução da Martins Fontes.
} 
ornamento exterior, mas de uma linguagem concisa e direta. Segundo já se repetiu muitas vezes, uma escrita seca. Isto, porém, não significa escassez vocabular, ou uma expressividade pouco inspirada. Trata-se, em verdade, de um modo da escrita política que possa dizer como que intrinsecamente a natureza das relações civis ${ }^{4}$. Dizer como que internamente, e não com ornamento exterior, evitando, ademais, "em todos os lugares, as palavras odiosas (...)" ${ }^{5}$. Um decoro da escrita que não é apenas uma adequação exterior, uma adequação entre "quem fala", "para quem fala" e "sobre o que fala", porém um tipo de decoro que supõe a adequação interna entre a língua da política, a escrita da política e o próprio âmbito político. A língua e a escrita da política não são políticas apenas quando têm por objeto o político.

Assim, trata-se de um modo de percepção do político que se estende para a concepção da própria escrita política e sua realização, por conseguinte não separando em campos isolados a lingua e o político. Não se trata tanto de constituir uma língua da política, mas de reconhecer o caráter político de toda língua, uma vez que a política é âmbito originário. A língua da política não depende tão somente do arbítrio daquele que escreve, pois ela é parte constituinte da vida política. Há um uso comum que precede qualquer uso particular, portanto um uso que antecede os usos e abusos que possam ser cometidos pelo escritor político. Roberto Esposito nos lembra: "afirmar que a política em Maquiavel é originária equivale a dizer que ela não tem origem. Que não existe algo de pré-político - como um estado de natureza - ao qual ela se siga, repelindo-o para um passado imemorial. A politica ocupa todo o borizonte do real (...). Isso quer dizer que não existe domínio da vida bumana que escape à necessidade da politica" ${ }^{6}$.

No pensamento de Maquiavel, há uma imbricação tal entre língua e política que não faria sentido uma pergunta sobre a "origem das línguas" ao modo como é feito por diversos pensadores da filosofia moderna. Se não há língua sem política, também não há política sem língua. A língua e a escrita política, desse modo, não são recursos artificiais no sentido de que estejam fora do próprio âmbito da política. Isto é, como se fossem esferas completamente isoladas que podem descrever o campo político olhando como que "de cima" e "de fora" dele.

Ainda no prefácio do Príncipe, Maquiavel já aponta para um modo de conceber o político que cruza as perspectivas "horizontal" e "vertical" a fim de que não reste um lugar fora a partir do qual uma visão parcial das coisas caia no discurso imaginativo criticado no capitulo XV do Principe. Nem apenas vista de cima, ou contada de baixo: "pois, assim como os que desenham as paisagens se colocam embaixo, na planície, para considerar a natureza dos montes e dos lugares elevados, e, para considerar a forma dos lugares baixos, colocam-se no alto, em cima dos montes,

\footnotetext{
4 Sobre este aspecto, veja-se: La Lingua e Le Lingue di Machiavelli [Atti del Convegno Internazionale di studi Torino, 2-4 dicembre 1999], 2001.

${ }^{5}$ MAQUIAVEL, História de Florença, p. 5.

${ }^{6}$ ESPOSITO, Pensamento Vivo: origem e atualidade da filosofia italiana, p. 62-63.
} 
para conbecer bem a natureza dos povos, é preciso ser príncipe, e, para conbecer a natureza dos príncipes, convém ser povo" 7 .

A língua em que se inscreve a política, e que se materializa na escrita, é, assim, a língua que repudia o ornamento exterior [ornamento estrinseco] e na qual se cruzam as perspectivas dos diferentes pontos de vista. Logo, é uma língua que não dá lugar nem para um além ou um aquém de onde se possa supor estar fora. Donde, faz ver, como que por dentro, a lógica imanente do corpo político. Ora, um corpo quando visto de fora mostranos apenas o comportamento aparente de suas funcionalidades, porém não nos faz ver as estruturas internas que são a razão de seu bom funcionamento. Em outros termos, aquilo que garante sua conservação. A necessidade, por isso, de uma língua, de uma escrita, que não se contentam com os efeitos, mas nos fazem ver as causas. Uma língua e uma escrita que operam como o anatomista que observa um corpo de dentro.

Este modo de fazer ver o corpo político a partir de dentro é a perspectiva mesma da escrita de Maquiavel. Com este princípio, ele afirma nos Discorsi: “(...) começarei discorrendo sobre as coisas que, ocorridas dentro da cidade e por deliberação pública, me pareçam dignas de maior atenção, acrescentando tudo o que delas decorria"8. Já no prefácio de sua História de Florença, reafirma-se este princípio de uma escrita imanente: “(...) decidi começar minha bistória pelo princípio de nossa cidade. E, como não é minha intenção ocupar o lugar albeio, descreverei com particularidades até 1434, somente aquilo que ocorren dentro da cidade, e sobre as coisas de fora só direi o que for necessário ao entendimento das de dentro"".

Ademais, não se deve olvidar, conforme indica Maquiavel, que os corpos políticos são corpos mistos $[\text { corpi misti }]^{10}$ e que, portanto, demandam um olhar agudo capaz de compreender a multiplicidade de sua constituição: elemento que torna ainda mais necessário que a escrita política diga do ponto de vista do interior do corpo político, ainda que não desconsidere as ações extrínsecas. Porém, estas últimas não interessam tanto per se, mas sim naquilo que possam interferir no interior do corpo político.

Assim, ante um corpo misto, a língua que o diz e a escrita que o expõe não podem falseá-lo com acréscimos. Nesse sentido, a língua da política deve resguardar-se das palavras empoladas [parole ampullose e magnifiche], dos acessórios dispensáveis, pois a dignidade da política se diz por si, se diz pela sua própria gravidade [gravita] ${ }^{11}$. É a tessitura

\footnotetext{
${ }^{7}$ MAQUIAVEL, O Principe, p. 4.

8 MAQUIAVEL, Discursos sobre a primeira década de Tito Livio, p. 12.

${ }^{9}$ MAQUIAVEL, História de Florença, p. 10.

10 MAQUIAVEL, Discursos sobre a primeira década de Tito Livio, p. 305.

${ }^{11}$ Cumpre observar que na curta sentença, na qual Maquiavel caracteriza sua escrita política, pode-se entrever, certamente, uma crítica aos excessos do uso do cânone humanista. Cânone que serve de modelo aos escritores políticos contemporâneos ao pensador florentino. Com efeito, segundo as afirmações de Maquiavel, pode-se indagar: o Príncipe está desprovido dos recursos retóricos e estilísticos que a tradição dos studia humanitatis recomenda observar na escrita política, ou faz uso diferenciado desta tradição ao qual se
} 
de uma escrita que espelha não propriamente o príncipe, mas as coisas que são postas diante de si, que dá a ver o que deve mostrar ${ }^{12}$. Os floreios e ornatos da escrita seriam como um espelho que atrai o olhar mais para sua moldura, do que para aquilo que reflete.

Ademais, em Maquiavel temos um modo de escrita que busca expressar a verdade efetiva das coisas [verità effetuale della cosa $]^{13}$. Sendo próprio da verdade não precisar de acréscimos, pois ela é sem eles, a escrita deve conformar-se a este princípio. Dessa maneira, o termo resistência, pode-se afirmar, nos faz ver aquela verdade efetiva das coisas que ele relaciona a partir de dentro do corpo político. Se Maquiavel utiliza o termo em momentos específicos de sua argumentação é porque concebe não poder trocá-lo por outro.

O termo resistência, como se verá adiante, expressa relações de forças singulares da vida política. Portanto, se não estamos no âmbito da escrita feita de exterioridades, os termos usados expressam com justeza aquilo que o autor quer nos fazer ver. São termos que, forjados no interior do corpo político, sobre este mesmo corpo retroagem. É, por isso, a natureza da escrita política em Maquiavel que nos permite pensar aqui a resistência a partir dos sentidos que o termo assume no Príncipe.

Partindo da adequação entre palavra [sermo] e coisa [res], fazendo uso da língua apropriada na qual se tece a escrita política, o fio da resistência é usado em dois momentos importantes da urdidura da trama do Príncipe. O primeiro deles é o capítulo $I X$, sobre o Principado Civil; o segundo é o célebre capitulo XXV, no qual a virtù e a fortuna estabelecem sentido relacional com base no termo resistência.

\section{II - Virtù, fortuna e resistência}

Iniciaremos de "trás pra frente", isto é, do capitulo XXV ao capitulo IX do Príncipe, abordando, em primeiro lugar, a resistência na relação entre virtù e fortuna. Desse modo, no célebre penúltimo capítulo do Príncipe se diz:

Comparo a fortuna a um desses rios impetuosos que, quando se iram, alagam as planícies, derrubam as árvores e as casas, arrastam terras de um lado para levar a outro: todos fogem dele, todos cedem a seu ímpeto sem poder detê-los em parte alguma (...). O mesmo acontece com a fortuna, que demonstra sua potência onde não encontra uma virtù ordenada,

vincula? Sobre tal aspecto, veja-se: Jean-Louis Fournel. Frontiere e Ambiguità nella Lingua del Principe: condensamenti e diffusione del significato.

12 FOUCAULT, As Palavras e as Coisas, p. 23.

13 MAQUIAVEL, O Principe, p. 75. 
pronta para resistir-lhe, e volta seu ímpeto para onde sabe que não foram erguidos diques nem barreiras para contê-la ${ }^{14}$.

Esta célebre passagem - tão revisitada pela tradição interpretativa do pensamento de Maquiavel - é, contudo, pouco apontada pelos estudiosos do pensador florentino a partir da relação dinâmica que caracteriza os âmbitos da virtù e da fortuna. Não obstante ser difícil afirmar com certeza, em virtude da longa duração de estudos sobre Maquiavel, a relação entre virtù e fortuna é, certamente, uma das questões mais discutidas, porém quase nunca referendadas à luz do termo que as relaciona: resistência.

No léxico político do Príncipe, aparece como o próprio da virtù o resistir, pois onde a fortuna nunca deixa de ser completamente impetuosa é porque não foi amortecida de forma adequada. Ou seja, não lhe foi feita a devida resistência. De modo que poderíamos dizer que a virtù de um príncipe, ou a virtù de um corpo político que não se deixa desintegrar facilmente é também um ato de resistência na medida em que se trata de não aceitar passivamente os golpes da fortuna, que, sempre fortes, podem facilmente esfacelar um corpo político vulnerável.

Temos então aqui, com as atuações da virtù e da fortuna, os elementos essenciais que caracterizam a lógica conflitual da resistência: duas forças contrárias, onde a suposta primazia de uma, ao investir contra a outra, gera um esforço reativo por parte daquele âmbito que está sob coação.

O sentido, contudo, de resistência no caso da relação entre virtù e fortuna não pode ser compreendido no registro retroativo do termo. Isto é, de reagir contra uma força dada depois, pois a fortuna é "árbitro de metade de nossas ações"15. Dessa maneira, a resistência contra a fortuna deve ser feita considerando que ela sempre mantém metade das ações, portanto que não se pode enfrentá-la frontalmente, em oposição direta, uma vez que, mantendo uma metade ativa do árbitro, ela nunca é vencida completamente ${ }^{16}$. A resistência feita em relação à fortuna não é o seu enfrentamento, a aniquilação completa de uma força contrária que premia o poder irresistível, porém a possibilidade de convivência com ela. Tal como na imagem do rio caudaloso proposta por Maquiavel: não se trata de torná-lo exíguo, mas de não se deixar levar pela torrente.

O exemplo de César Bórgia, dado no capitulo VII do Príncipe, é o caso mais expressivo de como, ainda que possuindo máxima virtù, a ação da fortuna não deixa de prevalecer, de fazer valer ativamente sua metade. Afirma Maquiavel que ele “(...) conquiston o estado com a fortuna do pai e com ela o perdeu, apesar de ter trabalhado de todas as formas e de ter

\footnotetext{
${ }^{14}$ MAQUIAVEL, O Príncipe, p. 122.

${ }^{15}$ MAQUIAVEL, O Príncipe, p. 121.

16 Sobre a especificidade do tratamento de Maquiavel, quando comparando com aqueles que também pensaram a fortuna, veja-se: SKINNER, MACHIAVEL.
} 
realizado todas as coisas que um homem prudente e de virtù deveria ter feito para deitar raizes naqueles

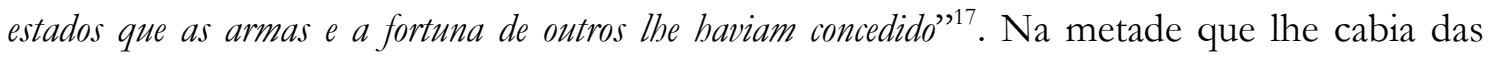
ações, ele agiu bem, resistindo, pois "para tudo havia encontrado remédio"; mas na metade que cabia à fortuna não havia resistência possível, "ao morrer seu pai, também ele estaria morrendo"18. A exemplaridade de Bórgia é dupla: mostra tanto como se deve agir com virtù, quanto ao lado disso também não deixa de mostrar a prevalência dos movimentos da fortuna.

A resistência aqui, portanto, não pode ser compreendida nos termos de uma ação feita a posteriori, como no caso, por exemplo, de uma ação contra uma usurpação de poder já realizada, ou ante a lei injusta já instituída. Em outras palavras, a resistência ocorrendo em momentos extraordinários, em que um corpo político dá sinais de desintegração. Entre a virtù e a fortuna, o sentido de resistência é o de uma ação antecipada, não ocorrendo em momentos extraordinários, nos quais resistir é um ato reativo (responder, revidar, ou se contrapor a uma ação já sofrida), e que justamente por isso nasce mais negativamente que positivamente, posto ser uma ação cujo princípio não é per si, mas por outro. Neste caso, não seria uma ação primeira, constitutiva; mas, como reação, uma ação segunda. Ora, quem resiste, o faz porque está sob a ação de outro. De modo que em seu interior, resistir guarda um sentido misto de negatividade e positividade. Negatividade no sentido de ser uma ação engendrada constitutivamente pela ação de outro, quem resiste (o faz por estar ameaçado); positividade, uma vez que, mesmo sob esta ação externa, engendra-se uma reafirmação daquilo que está ameaçado de perder-se. Apesar disso, nesse registro reativo, a resistência assemelha-se ao efeito, e não à causa.

No entanto, como já dissemos, não é de acordo com esta lógica, segundo a qual a resistência é uma ação reativa e feita em períodos extraordinários, portanto a posteriori, que a argumentação do Príncipe se pauta. Com efeito, a resistência ocorre naquela metade de nossas ações de que a fortuna não é senhora. Ademais, a boa virtù não é aquela que espera a chegada dos males para depois remediá-los. Ao contrário, trata-se de antecipar a possibilidade dos males para que as boas ordenações não permitam que eles ocorram. Porém, se ocorrerem, que sejam diagnosticados no início, pois só assim podem ser debelados ${ }^{19}$.

Dessa maneira, sentencia Maquiavel:

\footnotetext{
17 MAQUIAVEL, O Principe, p. 30.

18 MAQUIAVEL, O Principe, p. 36.

19 Trata-se não somente de resistir à fortuna, mas também ao tempo, que com ela opera em uníssono, tanto que podem ser, em muitos casos, confundidos. Por isso, o exemplo dos romanos, que no Príncipe mistura-se a outros exemplos, mas que nos Discorsi será o exemplo por excelência: “(...) os romanos, vendo à distância os inconvenientes, remediaram-nos sempre e nunca os deixaram desenvolver-se para evitar guerras, pois sabiam que as guerras não se evitam, mas se adiam em vantagem de outros. (...) Nunca lhes agradou aquilo que está todos os dias na boca dos sábios de nosso tempo: gozar o benefício do tempo, mas, ao contrário, o benefício de sua virtù e prudência, porque o tempo arrasa a sua frente todas as coisas e pode trazer consigo o bem como mal, e o mal como bem", (MAQUIAVEL, O Príncipe, p. 15).
} 
(...) precaver-se não somente contra as desordens presentes, como também contras as futuras, e evitá-las com toda a indústria porque, prevendo-as quando estão distantes, podem facilmente remediá-las, mas, esperando que se avizinhem, será tarde demais para o medicamento, pois a doença já se terá tornado incurável. Acontece nesse caso, o mesmo que dizem os médicos dos tísicos: no princípio o mal é fácil de curar e difícil de diagnosticar, mas, com o passar do tempo, não tendo sido nem diagnosticado nem medicado, torna-se fácil diagnosticá-lo e difícil de curá-lo. Assim, acontece nas coisas do estado (... $)^{20}$.

Desse modo, a virtù, pensada no registro da resistência, não é uma ação feita nos momentos em que a fortuna se abate sobre o corpo político. Uma vez que a ação da fortuna é incessante, e não só, mas também variável, a resistência que a virtù deve opor-lhe também deve ser incessante. Do contrário, não haverá resistência, pois em algum momento, cessando a virtù, a fortuna incessante prevalecerá. Logo, a sentença não pode ser outra, em relação àqueles que, acostumados com a boa sorte, acomodados pelos favorecimentos do momento, cessam de se precaver da fortuna, perdendo assim capacidade de lhe resistir: "se mudarem os tempos e as coisas mudam e ele não mudar seu modo de proceder, então se arruinará, (...), pois, se mudasse de natureza de acordo com os tempos e as coisas, não mudaria de fortuna" ${ }^{21}$.

Nesse sentido, resistir não é a exceção, mas como que a norma, é o próprio da ação política, uma vez que esta é tanto regida pela virtù, quanto é regida pela fortuna. O tempo da resistência se dilata por todo o percurso da vida do corpo político, e sua boa realização, que é incessante, não pode ser concebida na diferença entre dentro e fora, pois virtù e fortuna perfazem duas metades de um mesmo todo. Em outros termos, a resistência não é apenas ação operada na crise, mas a ação que antecipadamente não permita que a crise leve ao colapso do corpo político. Se este é o sentido da resistência na relação entre virtù e fortuna, qual o sentido no outro momento em que Maquiavel traz o termo à baila?

\section{III - Os grandes e o povo: resistência mútua}

A outra aparição, primeira na ordem cronológica dos capítulos, isto é, que ocorre no capitulo IX (Do principado civil) se dá também em umas das passagens mais citadas do Príncipe, e não apenas por isso importante, mas por tratar-se da passagem em que o autor nos faz ver os dois humores primários que constituem o corpo político.

20 MAQUIAVEL, O Principe, p. 14.

${ }^{21}$ MAQUIAVEL, O Principe, p. 123. 
(...) em todas as cidades, existem esses dois humores diversos [o povo e os grandes] que nascem da seguinte razão: o povo deseja não ser comandando nem oprimido pelos grandes, enquanto os grandes desejam comandar e oprimir o povo; desses dois apetites opostos, nasce nas cidades um destes três efeitos: principado, liberdade ou licença. O principado provém do povo ou dos grandes, conforme a ocasião tenha uma ou outra dessas partes. Pois, quando os grandes percebem que não

podem resistir ao povo, começam a conferir reputação a um deles e o fazem príncipe para poder, sob sua sombra, desafogar seu apetite. Também o povo, quando percebe que não pode resistir aos grandes, confere reputação a alguém e o faz príncipe, para ser defendido por sua autoridade ${ }^{22}$.

O capitulo IX, que se assenta totalmente nesta passagem, ocupa um lugar singular na primeira parte da obra. Este capítulo, por um lado, é precedido pelos capítulos em que Maquiavel descreve aqueles que chegam ao principado pelas armas (capitulo VI), pelas virtudes de outros (capitulo VII) e pelo crime (capitulo VIII). Por outro lado, ele é sucedido pelo capítulo que descreve os principados eclesiásticos (capitulo XI). Este último, o capitulo $X I$, segundo uma hipótese muito verossímil, sustentada por estudiosos como Gennaro Sasso, seria o último capítulo da primeira versão do Príncipe ${ }^{23}$. Em todos estes capítulos que antecedem e sucedem o capitulo IX, embora se suponha a existência dos dois humores do corpo político (os grandes e o povo), eles não se apresentam na gênese da constituição da forma de governo do corpo político. Ora, nesta gênese nós encontramos novamente a resistência.

Do muito que já se disse sobre os desejos dos dois humores, pouco se disse que, ambos sendo desejos, ainda que contrários, Maquiavel os articula aqui pelos vínculos da resistência ${ }^{24}$. Os elementos típicos de um conflito de resistência são dados por princípio: os grandes que objetivam oprimir, o povo, que reage a este desejo, resistindo com um desejo contrário: querer não ser oprimido. Logo, como em todo jogo conflitivo de resistência, tem-se um lado ativo e outro reativo. O leitor apressado, todavia, poderia replicar: nesta passagem não há resistência de fato, uma vez que Maquiavel não diz que o povo, ou os grandes resistem, mas sim que cada um "não podendo resistir" ao outro cede o caminho para o principado civil.

22 MAQUIAVEL, O Príncipe, p. 45.

${ }^{23}$ Hipótese sustentada com base na epístola a Francesco Vettori, de 10 de dezembro de 1513.

${ }^{24}$ Com efeito, Maquiavel voltará a falar dos dois humores da cidade, tanto nos Discorsi (no capítulo IV, livro primeiro), quanto na História de Florença (capitulo I, livro terceiro). Todavia, ainda que a compreensão da relação entre o povo e os grandes não se modifique, Maquiavel não fará, como no caso do Príncipe, o uso do termo resistência. 
Com efeito, isto que à primeira vista parece não ser resistência, é, em verdade, a resistência vista não apenas como algo reativo, ou seja, como reação, mas como positividade. Donde a forma expressiva astuciosa usada por Maquiavel, um tipo de "negação da negação" para fazer ver tal positividade. Não se diz positivamente: o "povo reagindo aos grandes", mas sim "os grandes não podendo resistir ao povo". Tal significa não apenas que o povo reage, mas que a sua ação é eficaz, de tal forma que os grandes não lhe podem resistir.

A boa resistência feita no interior do corpo político é aquela que ultrapassa o aspecto reativo, de modo que tende a anular a força opressiva inicial. Assim, de um caráter reativo, pois se trata de um desejo negativo, o do povo de não querer ser oprimido, se institui uma valência positiva da resistência. Mas, não se olvide que isto que se diz do povo, também se aplica aos grandes, tanto que Maquiavel usa a mesma forma expressiva: "o povo, não podendo resistir aos grandes".

Esta forma expressiva negativa [vedendo non potere resistere] usada para os dois humores da cidade nos aponta que uma concepção adequada, aquela que faz ver o jogo conflitivo da resistência em sua inteireza, deve considerar que no conflito constituinte, quando o lado que resiste sai do mero caráter reativo, o outro lado é que fica obrigado a resistir, passando a realizar a mesma ação do qual foi causa: como se o efeito se voltasse contra a causa. Mas, isto, que nessa primeira exposição do conflito pode ser dito tanto do povo em relação aos grandes quanto dos grandes em relação ao povo, ou seja, resistir, não permanece como uma antinomia de forças opostas inteiramente iguais que se anulam.

Há algo da resistência do povo que não pode haver na resistência dos grandes: "porque seus fins são mais honestos que os dos grandes, visto que estes querem oprimir, enquanto aqueles querem não ser oprimidos" ${ }^{25}$. Tal será reafirmado nos Discorsi, na consideração de que com o povo, e não com os grandes, deve ficar a guarda da liberdade, uma vez que pelo desejo de não serem dominados possuem "maior vontade de viver livres, (...) de tal modo que, sendo os populares encarregados da guarda de uma liberdade, é razoável que tenham mais zelo e que, não podendo eles mesmos apoderar-se dela, não permitiram que outros se apoderem"26.

\section{IV - Uma conclusão aberta: resistir como atitude política ininterrupta}

Nas duas vezes que Maquiavel traz à baila a lógica da resistência, utilizando-se do termo, o faz em dois momentos crucias da argumentação do Príncipe. Ademais, ele não se deixa levar pelo caráter mais superficial da resistência, isto é, de apresentar-se somente como ação reativa. Trata-se de pensá-la com argúcia. Arguto, na medida em que nos faz ver

${ }^{25}$ MAQUIAVEL, O Príncipe, p. 46.

${ }^{26}$ MAQUIAVEL, Discursos sobre a primeira década de Tito Livio, p. 24. 
a resistência como instância não apenas permanente, mas como elemento constitutivo da vida política. Ela está na gênese do corpo político, não sendo em relação a este um momento posterior. Se o conflito é a lógica imanente do corpo político, em virtude de seus humores contrários, pensar a resistência como algo extraordinário é supor que a estabilização dos conflitos seja a garantia de sua superação. Ao contrário, assim proceder é tornar-se presa fácil dos golpes da fortuna, ou dos grandes.

A boa resistência é aquela que nunca deixa de agir, mas permanece atenta, mesmo quando os ventos parecem que sopram favoráveis. Boa também porque nunca permanece reativa, mas faz de sua negatividade inicial um meio para se chegar à positividade final. É esta resistência que, nesses tempos de avanço dos reacionarismos, no momento em que os grandes incidem sobre nós, somos desafiados a construir. Ademais, sem perder de vista que nosso desejo de não querer ser oprimido é mais honesto; e, ao final desta resistência que nos é demandada por nossas determinações histórico-sociais, não se diga apenas que "nós resistimos", mas que eles "não puderam resistir a nós".

\section{INSIDE THE POLITICAL BODY, THE SENSES OF RESISTANCE: THE TEXTURE OF MACHIAVELLI}

Abstract: Even if Machiavelli is not in the scope of the political tradition of the thinkers who theorize about the right of resistance, it is possible to address the question of resistance as a constitutive element of political life in the thought of the Florentine author. That can be done based on two moments when the term resistance, in its verbal and nominal forms, occurs in the scope of argumentation in The Prince. Here it is not proposed a simple exercise of political vocabulary, being satisfied with the recognition and the location of the term. It is the conception of the Machiavelli's political writing itself that allows us to think the importance of the term in the political reflection: question justified in the first part of this paper. Then, based on the nature of the political writing we discuss about the two moments when Machiavelli uses the term resistance as a mean of expression and comprehension of the relation between virtù and fortuna, as well as the opposition between the nobles and the people.

Keywords: Language - politics - resistance.

\section{Referências Bibliográficas}

Obras de Maquiavel:

MACHIAVELLI, Niccolò. Opere. Vol. I. Torino: Einaudi-Gallimard, 1997. Diálogo sobre nossa lingua e Discurso sobre as formas de governo de Florença. Trad. Helton Adverse e Gabriel Pancera. Belo Horizonte: Editora da UFMG, 2010. 
Discursos sobre a primeira década de Tito Livio. Trad. MF. São Paulo: Martins Fontes, 2007.

Epistolario (1512-1527). Trad. esp. Stella Mastrangelo. Ciudad de Mexico: Fondo de Cultura Económica, 2013.

História de Florença. Trad. MF. São Paulo: Martins Fontes, 2007.

O Principe. Trad. Maria Júlia Goldwasser. São Paulo: Editora Martins Fontes, 2010. Il Principe. Milano: Mondadori, 1994.

Obras sobre Maquiavel:

ALTHUSSER, Louis. Maquiavelo y nosotros. Trad. esp. Beñat Baltza Álvarez, Raúl Sánches Cedillo e Carlos Prieto del Campo. Madrid: Ediciones Akal, 2004.

Cultura e Scrittura di Machiavelli. Atti del Convegno di Firenze-Pisa (27-30 ottobre-1997). Roma: Salerno Editrice, 1998.

DOTTI, Ugo. Machiavelli Rivoluzionario. Vita e opere. Roma: Carocci editore, 2005.

ESPOSITO, Roberto. Ordine e Conflito: Machiavelli e la letteratura politica del Rinascimento italiano. Napoli: Luguori editore, 1984.

La politica e la storia: Machiavelli e Vico. Napoli: Luguori editore, 1980.

Pensamento Vivo. Origem e atualidade da filosofia italiana. Trad. Henrique Burigo. Belo Horizonte: Editora da UFMG, 2013.

La Lingua e le lingue di Machiavelli. Atti del Convegno internazionale di studi - Torino, 2-4 dicembre 1999. Città del Castelo: Leo S. Olschki Editore, 2001.

PROCACCI, Giuliano. Machiavelli nella cultura europea dell'età moderna. Roma-Bari: Editori Laterza, 1995.

SASSAO, Gennaro. Niccoló Machiavelli. Vol. II. La Storiografia. Bologna: Il Mulino, 1993.

SKINNER, Quentin. Machiavel. Trad. De l'anglais Michel Plon. Paris: Éditions du Seuil, 1989.

VIVANTI, Corrado. Nicolau Maquiavel nos tempos da política. Trad. Sergio Maduro. São Paulo: Martins Fontes, 2016. 
Obras de outros autores

ESPINOSA, Baruch. Tratado Político. Trad. Diogo Pires Aurélio. São Paulo: Martins Fontes, 2009.

FOUCAULT, Michel. As palavras e as coisas. Uma arqueologia das ciências humanas. Trad. Salma Tannus Muchail. São Paulo: Martins Fontes, 1987.

GARIN, Eugenio. La Cultura Filosofica del Rinascimento Italiano. Ricerche e Documenti. Firenze: Sansoni, 1979.

LEFORT, Claude. As Formas da História. Trad. Luiz Roberto Salinas Fortes e Marilena de Souza Chaui. São Paulo: Brasiliense, 1979.

Desafios da escrita política. Trad. Eliana de Melo Souza. São Paulo: Discurso Editorial, 1999.

KRISTELLER, Paul. Tradição clássica e pensamento do Renascimento. Lisboa: Edições 70, 1995. 